九州大学学術情報リポジトリ

Kyushu University Institutional Repository

The Effect of Integrated Play Therapy on SelfExpression and Depression in Elderly Women Living Alone in Rural Areas

KIL, Tae Young

Institute of Agricultural Science, Chungnam National University

RYU, Han Su

School of Social and Child Welfare, Woosong University

YAMAUCHI, Nobuhiko

Department of Animal and Marine Bioresource Science, Faculty of Agriculture, Kyushu University

https://doi.org/10.5109/1955669

出版情報：九州大学大学院農学研究院紀要. 63 (2)，pp.457-467，2018-09-01. Faculty of Agriculture, Kyushu University

バージョン :

権利関係 : 


\title{
The Effect of Integrated Play Therapy on Self-Expression and Depression in Elderly Women Living Alone in Rural Areas
}

\author{
Tae Young KIL ${ }^{1 *}$, Han Su RYU ${ }^{2 *}$ and Nobuhiko YAMAUCHI \\ ${ }^{1}$ Institute of Agricultural Science, Chungnam National University, Daejeon, 34134, Republic of Korea \\ ${ }^{2}$ School of Social and Child Welfare, Woosong University, Daejeon, 34606, Republic of Korea \\ ${ }^{3}$ Department of Animal and Marine Bioresource Science, Faculty of Agriculture, \\ Kyushu University, Fukuoka, 819-0395, Japan \\ (Received May 1, 2018 and accepted May 8, 2018)
}

\begin{abstract}
The aim of this study is to investigate the effects of an integrated play therapy program on self-expression, depression, and psychosocial well-being among elderly women who live alone in rural areas. The study was conducted on a group of elderly women, aged 65 and over, who were living alone. Researchers selected one village in the township of A-country, Chungcheongnam-do, South Korea. Data were collected from 24 experimental groups and 24 non-participating control groups. The program was applied to the experimental group for a total of eight weeks (one two-hour session per week). An analysis compared the results of the non-identical control group before and after the program; the effect of the program was measured by assessing participants using a follow-up test, before, immediately after, and ten weeks after the program. The results showed that levels of self-expression increased significantly in the experimental group, from 2.96 before the program, to 3.45 immediately after the program, and 4.13 ten weeks later. Rates of depression decreased significantly in the follow-up tests, measuring $0.85,0.67$, and 0.21 before, after, and ten weeks later. These results show that the play therapy program was effective and had a continuous effect on elderly participants. This study confirms that integrated play therapy is an effective program for developing self-expression and reducing depression among elderly women who live alone in rural areas. Based on these results, this article discusses the impact of the program on self-expression and depression among elderly women who live alone in rural areas; it proposes a policy as a basis for operating and using integrated play therapy to help vulnerable elderly people.
\end{abstract}

Key words: Elderly women, Rural areas, Self-expression, Depression, Integrated play therapy

\section{INTRODUCTION}

Korea is simultaneously experiencing a low birth rate and an aging population. As the elderly population increases, the proportion of elderly people living alone, society's most vulnerable demographic group, has been steadily increasing, from 8.9\% in 1990 to $19.1 \%$ in 2016. In this context, the social-security system and policies for elderly people have become an increasingly important social issue (Statistics Korea, 2017). In particular, the number of elderly people living alone in rural areas has increased by $53 \%$, from 279,000 households in 2000 to 428,000 households in 2015 , twice the rate of those living in cities. The problem has also been exacerbated by the fact that the number of elderly women living alone is rising fast (National Agricultural Cooperative Federation, 2017). For elderly widows living alone in rural areas, family members, including sons and daughters, must provide social and economic, as well as emotional and psychological support. Widows who live alone, without any members of their families nearby, are particularly vulnerable to mental health issues, such as loneliness, solitude, and depression, as well as economic

* Co-corresponding author: Tae Young KIL, Ph. D; Address: 99 Daehak-ro (st), Yuseong-gu, Daejeon, 34134, Republic of Korea, E-mail: taeyoungkil@cnu.ac.kr and Han Su RYU, Ph. D; Address: 171 Dongdaejeon-ro, Dong-gu, Daejeon, 34606, Republic of Korea, E-mail: hansu@wsu.ac.kr Tel: +82-42630-9262; Fax: +82-42-630-9829 and health issues. As a result, more and more people are demanding a social system that takes some responsibility for these elderly women (Statistics Korea, 2017).

For elderly women who live alone in rural areas, self-expression is important; it plays a key role in developing and maintaining interpersonal relationships (Collins and Miller, 1994). Depression is known to be a chronic condition that is frequently experienced by isolated elderly women. Given its high prevalence, intervention through a therapy program can play an important role during the acute and maintenance phases of treatment (Ryan and Crawford, 2002). However, single women who lack the support of family or society suffer from emotional and social difficulties that make it difficult to adequately express their emotions or opinions. As a result, they often develop a passive attitude toward life; their self-confidence sinks lower and lower, until their mental health becomes unstable (Jacobs et al., 2012). Poor mental health causes their capacity for self-expression to deteriorate further; it is also closely linked to depression and suicidal ideation. Enabling people who suffer from this condition to recover their values and positive interpersonal relationships through healthy, active forms of self-expression can help them to rediscover a meaningful and rewarding purpose in life (Alberti and Emmons, 1970; Hackeney and Ney, 1973). It therefore follows that, if elderly women who live alone in rural areas can learn skills that enable them to cope effectively with self-expression and reduce depression through a group therapy program, various complex psychological 
and social problems can be prevented and their quality of life can be enhanced in many ways.

Integrated play therapy for elderly people creates a form of wholeness that cannot be achieved through individual play. It achieves this by combining content from fields of play such as music, where mental recovery can be achieved through an integrated experience-centered approach. Engaging in art making can build self-efficacy and emotional stability, while language and literature enhance linguistic functions, helping elderly participants find ways of expressing their latent needs. While physical activities boost and stimulate emotional health, cognitive games can improve interpersonal relationships and sociality. In the area of ordinary life or "living," play activities enhance self-confidence and sense of achievement; traditional play provides emotional stimuli and enhances cognitive functions. Hands-on play activities can be beneficial across various programs (Shin, 2014). An integrated approach is particularly valuable because it pulls together the participants' life experiences, links content across different program activities, connects communities, and integrates and reconstructs the knowledge and ideas of individual elderly women (Shin, 2008; Shin, 2014). The present study proposes constructing activities in each area so as to form an integrated approach, allowing a significant intervention in the lives of isolated elderly women. This approach is expected to improve the physical and mental health and sociality of elderly women. By providing opportunities for the women to take part in creative and healthy leisure-time activities, this approach can diagnose and evaluate their status and enhance their ability to adapt to real life. Ultimately, it is expected to drive their self-expression in the direction of positive change and happiness, reducing symptoms of depression.

Many studies conducted in South Korea and abroad have applied play therapy programs to groups of people. These studies have revealed that self-expression and depression are related variables (Ledyard, 1999; Stephenson, 2006; Kim, 2008; Kim, 2011; Youn, 2012; Jacobs et al., 2012; Kapitan, 2012; Case and Dalley, 2014; Shin and Chung, 2015; Hong et al., 2015; Kil, 2017; Kapitan, 2017). However, most previous studies have involved children or infants; few have introduced integrated play therapy to elderly women living alone in rural areas; for this reason, its therapeutic effects on selfexpression and depression among vulnerable elderly people are still unknown. By using an integrated approach to bring group play therapy to this population, the present study makes a significant contribution that has the potential to genuinely change life experiences.

The purpose of integrating individual play therapies and introducing them to elderly women who live alone in rural areas is to enhance cognitive, psychological, and social aspects of their changing experience of life, making the aging process work more positively for them (Kim, 2000). When isolated elderly women are given an opportunity and place to meet others, their depression levels fall and their capacity for positive self-expression expands; as a result, they are able to find new meaning in life. An intentional intervention can also be used as a preventive service, helping to enhance their overall independence and alleviate many chronic health conditions, including depression (Potts, 1997; Yeh and Lo, 2004). Kim (2013) has verified the effects of such integrated play therapy, reporting that the depression scores of 20 elderly people in a nursing care facility decreased after they engaged in a combination of music, art, language, literature, games, physical activities, and living and traditional play for five weeks. Shin and Chung (2015) integrated the areas of music, art, language and literature, physical activity, cognitive games, living, traditional play, and the environment to offer an integrated ten-week program for elderly people in the initial stages of dementia; the program was effective in significantly improving their levels of depression. Kil (2017) integrated the areas of music, art, language and literature, physical activity, cognitive games, living, traditional play, and hands-on play; 20 disabled elderly people who took part in this eight-week program significantly increased their capacity for self-expression and effectively reduced symptoms of depression, results that were subsequently maintained.

The present study engaged isolated elderly women in a program of integrated play therapy and verified the effects of the intervention. The primary aim of the study has been to help isolated elderly women expand their capacity for self-expression through the joyful activity of play, reducing depression (a negative emotion) and ultimately enhancing their quality of life. The program explored the effects of this intervention in relation to the following research questions. First, does integrated play therapy have a short-term or prolonged effect on the self-expression of elderly women living alone in rural areas? Second, does integrated play therapy have a short-term or prolonged effect on depression in elderly women living alone in rural areas?

\section{THEORETICAL BACKGROUND}

\section{Integrated Play Therapy and Elderly Women Living Alone in Rural Areas}

Elderly women who live alone in rural areas can have a very personal experience of talking to themselves through play. While engaging in such activities, they use tools that facilitate play to become immersed and interested in a particular activity; these can easily lead to enjoyment of its diverse aspects (Landreth, 2013). Play therapy, developed in 1942, has recently received growing attention. The most important aspect of the play therapy used in this research is that it allowed the elderly women participating in-group play therapy to share a play object that symbolized themselves with other group members and to receive feedback (Landreth, 2012). The therapy encouraged participants to adopt a wide range of roles, expressing themselves and interacting with each other. This set of activities helped them learn the psychosocial process of learning through unaffected participation and encouragement (Landreth et al., 2009). 
As they grow older, elderly women living alone in rural areas require more relationships that are interpersonal and support from others. This is because they have lost the roles they used to play, resulting in a deterioration of physical functions, restrictions in daily life, and health issues. These elderly women also depend on others to meet their basic needs. In particular, they have a strong tendency to depend more on unofficial systems (relationships with children and relatives), which represent the very core of lifetime interrelationships (Suh, 1990; Sutherland and Murphy, 1995). These elderly women must therefore learn healthy behaviors and modes of self-expression as they approach the initial stages of depression; it is important for them to explore the procedures and consequences of life, given that human development occurs throughout an entire lifetime. Unfortunately, the social welfare services provided by the government, including lessons on how to navigate existing life- and health-management systems, still lack inclusiveness. There is also a tendency to ignore the question of who will provide emotional support or assistance to elderly women living alone in rural areas, even though they may need totally different types of support as they get older (Granbom et al., 2014; Rittirong et al., 2014).

Integrated play therapy applies the systematic intervention of a trained play therapist and the therapeutic power of play, helping elderly people maintain an optimal state of health by preventing or resolving their psychological and social problems through play (Schaefer \& O' Connor, 1994). By using an integrated approach that creates an interrelationship between programs, this form of play therapy can be applied within a more eclectic framework that integrates diverse perspectives; it intentionally intervenes to resolve problems with self-expression and general psychological disorders, such as depression, by combining various therapies and skills to integrate participants' personal and social experiences in a harmonious manner (Weir, 2008; Drewes et al., 2011). Above all, this approach offers a stable and consistent emotional stimulus for positive life changes that can be fully used in daily life, even after the program has finished (Shin, 2014; Schaefer, 2003).

\section{Self-Expression and Depression}

The primary function of self-expression is to develop relationships; it supports established relationships with close friends and family members. Among elderly women who live alone in rural areas, self-expression is related to self-purification, social control, and social verification (Parker and Parrott, 1995). The family or neighbor system plays a very important role in alleviating depression, a mental disorder most frequently observed in the elderly. The prevalence of depression is particularly high among isolated elderly women because they receive little emotional support from this primary support group; these women have lost their family systems. Given that the onset of depression is earlier among isolated elderly women than in other demographic groups, isolation inevitably has a serious impact on their bodies and mental health (Taqui et al., 2007).

However, if these women expand their capacity for self-expression, they are highly likely to develop their emotional range and recover the feeling that life has meaning. Feeling grateful for life lowers the risk of depression (Krause, 2007). Moreover, finding a way to respond appropriately to problems that occur during interactions with the environment can prevent negative emotions such as depression (Desrosiers et al., 2005). Play therapy is based on the belief that participants can feel fully satisfied by interacting with and responding to people other than family members. They feel attractive and capable of loving others. They need and are able to experience emotions that are important and valued in developmental terms. In addition, play therapy can be maximized to enhance self-expression and reduce depression by enabling elderly participants to experience aging, not as a regressive process, but as a kind of accumulative or useful asset; this approach can enhance their static emotional experiences (Sung, 2009).

To date, although many studies of the mental health of elderly people have focused on issues related to the increasing elderly population, most studies have involved qualitative research (Won and Lee, 2016). The present study has conducted empirical clinical research on elderly women living alone in rural areas; its goal has been to identify a comprehensive emotion-focused approach and to develop a consistent strategy for increasing their capacity for self-expression and addressing life experiences that involve depression.

In recent years, more and more researchers have shown an interest in self-expression and depression, producing a number of studies (Chun et al., 2005; Jacobs et al., 2012; Kapitan, 2012; Lee, 2012; Case and Dalley, 2014; Hong et al., 2015; Kapitan, 2017). However, most of this research has adopted the piecemeal approach used to investigate infants and children. To treat elderly women living alone in rural areas, it is important to use a more integrated approach, focusing on the relationship between self-expression and depression. As few studies have applied an integrated program of play therapy to this population and verified its effects, the present study has examined earlier research on the effects of more limited forms of intervention on self-expression and depression among elderly women. Kim (2004) has reported that providing art therapy to isolated lowincome elderly women in rural areas helped them to actively express themselves and experience positive emotions, thereby lowering their levels of depression. Yoon and Shim (2013) have shown that group music therapy reduced depression among elderly women who lived alone. Jang (2015) has reported that group art therapy alleviated feelings of depression among isolated, low-income elderly women; Baek and Oh (2017) have reported that isolated elderly women who participated in art therapy were able to positively accept and integrate their lives through active self-expression, releasing negative experiences and emotions that they had previously suppressed. McCaffrey (2007) has reported that gardening and art therapy, which are classified as 
"living" activities, helped elderly women cope with both minor and serious depression. Reynolds et al. (2008) have shown that an art therapy program applied to women aged 65-72 had a significant effect on personal experiences and the broader social context, not only enhancing participants' capacity for self-expression, but also strengthening their decision-making and alleviating depression.

\section{RESEARCH METODS}

\section{Research Subjects}

The subjects of this study were elderly women (aged 65 or over) living in the township of A-country, Chungcheongnam-do in South Korea. There were 48 subjects in total, of whom 24 were in the experimental group, participating in play therapy, and 24 were in the control group. Two weeks before the program began, researchers explained the study's purpose and research process to the experimental and control groups at the local Town Hall; the experimental group was selected from among those who wanted and were able to actively participate in the program. To compensate for the expected dropout rate in the experimental group, the sample size was set at 25 persons when subjects were recruited. One person dropped out of the experimental group midway through the process and was therefore excluded from the analysis. To maintain homogeneity between the groups, smaller groups with shared social demographic characteristics were formed, as can be seen in Table 1. Thus, the experimental participants were divided into two groups, the first including 12 women aged 71-80 (50\%) and the second including 10 women aged 81 or over $(42 \%)$. The control participants were also divided into two groups, of which the first consisted of 16 women aged $71-80(67 \%)$ and the second of 6 women, aged 81 or over (25\%). In terms of educational background, 17 participants were elementary-school graduates $(71 \%)$, followed by 4 who were middle-school graduates $(17 \%)$ in the experimental group. In the control group, 15 participants were elementary-school graduates (63\%) and 5 were middle-school graduates (21\%). In terms of religion, the experimental group included 9 Buddhists (38\%) and 8 Christians (33\%), while the control group included 10 people with no declared religion (42\%) and 8 Buddhists (33\%). When it came to health status, 21 women (88\%) in the experimental group and 22 women (92\%) in the control group were known to have various diseases, making up a high proportion of the group. In terms of subjective economic condition, 17 women $(71 \%)$ in the experimental group considered their economic status to be average, followed by 5women (21\%), who considered themselves poor. In the control group, 23 persons (96\%) considered themselves average and 1 person (4\%) felt that her economic condition was above/below average.

\section{Research Design and Data Collection}

To verify the effectiveness of integrated play therapy for elderly people, this study compared the two experimental and control groups before and after the educational program, using the non-equivalent control group to provide pre- and post-test results. As indicated in Table 2, a pre-test was conducted on the day of intervention. This was followed by a post-test, conducted at the end of the intervention and a follow-up test, carried out ten weeks after the end of the intervention. To collect data, a primary questionnaire survey on

Table 1. Socio-demographic characteristics of control and experimental group

\begin{tabular}{|c|c|c|c|c|c|}
\hline & \multirow{2}{*}{ Demographic Variable } & \multicolumn{2}{|c|}{ Experimental group $(n 1=24)$} & \multicolumn{2}{|c|}{ Control group $(n 2=24)$} \\
\hline & & Frequency & Percentage (\%) & Frequency & Percentage (\%) \\
\hline \multirow{3}{*}{ Age } & Below 70 years old & 2 & 8.0 & 2 & 8.0 \\
\hline & $71 \sim 80$ years & 12 & 50.0 & 16 & 67.0 \\
\hline & More than 81 years & 10 & 42.0 & 6 & 25.0 \\
\hline \multirow{4}{*}{$\begin{array}{c}\text { Education } \\
\text { level }\end{array}$} & Lack of schooling & 2 & 8.0 & 2 & 8.0 \\
\hline & Elementary School Graduated & 17 & 71.0 & 15 & 63.0 \\
\hline & Middle School Graduated & 4 & 17.0 & 5 & 21.0 \\
\hline & High school Graduated & 1 & 4.0 & 2 & 8.0 \\
\hline \multirow{4}{*}{ Religion } & Buddhism & 9 & 38.0 & 8 & 33.0 \\
\hline & Christian & 8 & 33.0 & 4 & 17.0 \\
\hline & Catholic & 5 & 21.0 & 2 & 8.0 \\
\hline & Atheism & 2 & 8.0 & 10 & 42.0 \\
\hline \multirow{2}{*}{ Health status } & Good & 3 & 12.0 & 2 & 8.0 \\
\hline & Various disease & 21 & 88.0 & 22 & 92.0 \\
\hline \multirow{3}{*}{$\begin{array}{l}\text { Subjective } \\
\text { economic } \\
\text { condition }\end{array}$} & Poor & 5 & 21.0 & 0 & 0.0 \\
\hline & Average & 17 & 71.0 & 23 & 96.0 \\
\hline & Rich & 2 & 8.0 & 1 & 4.0 \\
\hline
\end{tabular}


Table 2. Verification model of the effectiveness of integrated elderly play therapy

\begin{tabular}{ccccc}
\hline Group & Pre & Intervention & Post & Follow-up \\
\hline Experimental group & $\mathrm{O}_{1}$ & $\mathrm{X}^{*}$ & $\mathrm{O}_{2}$ & $\mathrm{O}_{3}$ \\
Control group & $\mathrm{O}_{4}$ & - & $\mathrm{O}_{5}$ & $\mathrm{O}_{6}$ \\
\hline
\end{tabular}

": X1: Death preparation education program

Pre: Day of intervention / Post: End of intervention / Follow-up: After 10 weeks

self-expression and depression was administered to all 48 elderly women before the start of the program, on January 5, 2017. The same questionnaire was administered again on the final day of the program, which was March 9, 2017. It was then administered a third time, on May 20, 2017: ten weeks after the end of intervention. To ensure that the study subjects were treated ethically, researchers explained informed consent, voluntary consent, confidentiality, and the right of rejection. The study subjects signed documents to provide written consent. Moreover, as the subjects had little experience of participating in educational programs, researchers discussed an appropriate dynamic for the group and prepared for potential situations by setting clear boundaries to avoid causing stress to participants. The main researcher, a certified elderly play therapist, managed the program and collected data with the help of two research assistants, one social welfare worker, and two volunteers, who were university students.

\section{Measuring Tools}

\section{1) Self-Expression}

Self-expression was measured using the SelfDirected Assertiveness Training (SDAT) scale developed by Rakos and Shroeder and translated by Byun and Kim (1980). The scale consisted of a total of 20 questions, of which 9 evaluated the extent to which self-expressive elements were included in the content reported by the subject, 7 determined whether self-expressive elements were observed in paralinguistic communications, and 4 evaluated non-verbal self-expressive elements. Responses ranged from "absolutely not" (1 point) to "definitely yes" (5points). The higher the score, the more expanded the self-expression. The Cronbach's $\alpha$ for this study was .929 .

\section{2) Depression}

The Korean version of the Geriatric Depression Scale (KGDS), standardized by Jung et al. (1997), was used to measure levels of depression. The scale was developed by Yesavage and Brink in the early 1980s; it is effective in evaluating levels of depression among elderly people and mental patients in the community. A dichotomic scale, it consists of 30 questions, of which 16 are negative and 14 are positive. In responses to negative questions, 1 point is assigned to "yes" answers and 0 points to "no" answers. Responses to positive questions use a reverse coding, with 0points assigned to "yes" and 1point to "no." In other words, the higher the score, the more severe the level of depression. The Cronbach's $\alpha$ in this study was .946 .

\section{The Structure of the Integrated Play Therapy Program}

This study focused on helping elderly women who lived alone in a rural area to recover from psychological and social problems related to self-expression and depression and to positively reconstruct the meaning of life. This study was based on research carried out by Shin (2014) and Kil (2017), in which integrated play therapy was applied to elderly people and the effects of the intervention were verified. To maximize the therapeutic power of play, every individual was respected and cared for. Each participant was allowed to fully enjoy the process of participating in play activities. Every effort was made to draw out the potential capacities of individual participants so that they could maintain and further develop their feelings of happiness. The integrated play therapy was progressed as follows: the integrated approach method $\rightarrow$ determined the details of activities $\rightarrow$ constructed and connected the details of activities and experiences $\rightarrow$ implemented the integrated application $\rightarrow$ produced feedback. The program incorporated these procedures in an integrated manner that individually designed each role and intervention effect to ensure that participants were able to enhance their physical and mental health, sociality, sense of happiness, and capacity to enjoy healthy habits and adapt to daily life. The integrated play therapy was designed to enhance the participants' cognitive, psychological, and social abilities by integrating the individual areas of music, artistic work, language and literature, physical activity, cognitive games, living, traditional play, and hands-on play, as well as activity-related considerations including the aim, content, and method of each activity and aspect of brain development. As a whole, the integrated play therapy sessions were designed to provide easy and interesting access to elderly people. The program had three sections: an initial stage ( $1^{\text {st }}-2^{\text {nd }}$ sessions $)$, a middle stage ( $3^{\text {rd }}-6^{\text {th }}$ sessions $)$, and a final stage $\left(7^{\text {th }}-8^{\text {th }}\right.$ sessions $)$. In each section, the program consisted of eight sessions held once a week; each session included an introduction and lecture (50 minutes), a break (10 minutes), and a lecture, with time for sharing opinions (30 minutes).

The activities for each stage of the integrated play therapy program are presented in detail in Table 3. During the initial stage ( $1^{\text {st }}-2^{\text {nd }}$ sessions $)$, the participants made name tags with crayons to show their unique personalities and used the name tags as a pictorial attendance book until the end of the session, to create rapport and intimacy among group members and between members and the play therapist. A songbook was created by 
Table 3. Composition of integrated elderly play therapy program

\begin{tabular}{|c|c|c|}
\hline $\begin{array}{c}\text { Step } \\
\text { ( Session ) }\end{array}$ & Goal & Contents and integrated principles of play therapy activities by session \\
\hline \multirow{2}{*}{$\begin{array}{l}\text { Initial } \\
\text { stage } \\
(1-2)\end{array}$} & \multirow{2}{*}{$\begin{array}{l}\text { Lapo formation } \\
\text { Ice-Breaking to form } \\
\text { intimacy and trust } \\
\text { between group members } \\
\text { and play therapists }\end{array}$} & $\begin{array}{l}\text { - Making the name tag / Introduce me and know friend's name (Art work area) } \\
\text { - Who are you / Singing (Music area) } \\
\text { - Introduce me / Talk to you (Linguistic literature area) } \\
\text { - Balloon volleyball / Relationship with others (Physical exercise area) }\end{array}$ \\
\hline & & $\begin{array}{l}\text { - Greeting a friend / Turning song (Music area) } \\
\text { - Korean paper flower making (Art work area) } \\
\text { - Legs subtract game / Affinity (Traditional play area) } \\
\text { - Make picture puzzle / Cooperation, Affinity (Cognitive game area) }\end{array}$ \\
\hline \multirow{4}{*}{$\begin{array}{l}\text { Middle } \\
\text { stage } \\
(3-6)\end{array}$} & \multirow{4}{*}{$\begin{array}{l}\quad \text { Integrative access } \\
\quad \text { activity } \\
\text { - Music area } \\
\text { - Art area } \\
\text { - Language literature area } \\
\text { - Physical exercise area } \\
\text { - Cognitive game area } \\
\text { - Living area } \\
\text { - Traditional play area }\end{array}$} & $\begin{array}{l}\text { - Singing with an old friend (Music area) } \\
\text { - My proud hand (Art work area) } \\
\text { - Korean dance / Improve expression ability (Physical exercise area) } \\
\text { - Take it when you get } 10 \text { / Affinity (Cognitive game area) }\end{array}$ \\
\hline & & $\begin{array}{l}\text { - Sing a children's song / Fat man's house (Music area) } \\
\text { - Children's poem reading / Looking at the moon (Linguistic literature area) } \\
\text { - Drawing a hope tree (Art work area) } \\
\text { - Chair gymnastics (Physical exercise area) }\end{array}$ \\
\hline & & $\begin{array}{l}\text { - Hands-on play/ Prevention of dementia by finger yoga (Physical exercise area) } \\
\text { - Making Maracas (Art work area) } \\
\text { - Praise and share well-wishing remarks (Language literature area) } \\
\text { - Music appreciation / Flower waltz (Music area) }\end{array}$ \\
\hline & & $\begin{array}{l}\text { - Maracas and tabors ensemble (Physical exercise area) } \\
\text { - Making marbles / Making a mountain area (Traditional play area) } \\
\text { - Gyun-woo and Jing-nyuh (Language literature area) } \\
\text { - Egg plate play (Cognitive game area) }\end{array}$ \\
\hline \multirow{2}{*}{$\begin{array}{l}\text { Final } \\
\text { stage } \\
(7-8)\end{array}$} & \multirow{2}{*}{$\begin{array}{l}\text { Activity and } \\
\text { preparation for } \\
\text { finishing the program } \\
\text { Discussion and exchanged } \\
\text { opinions about the } \\
\text { program, sharing joyful } \\
\text { experiences and precious } \\
\text { memories, feedback and } \\
\text { evaluation reviews }\end{array}$} & $\begin{array}{l}\text { - Crepe balloon play (Physical exercise area) } \\
\text { - My home where I lived / Collective recall (Art work area) } \\
\text { - Making half-moon rice cake (Living Area) } \\
\text { - Playing the fan-jegi (Traditional play area) }\end{array}$ \\
\hline & & $\begin{array}{l}\text { - Newspaper play / Folk song singing (Music area) } \\
\text { - Hopscotch (Traditional play area) } \\
\text { - You are a flower, I am a flower (Living area) } \\
\text { - Talking about your participation in the play }\end{array}$ \\
\hline
\end{tabular}

selecting the participants' favorite songs; this book was designed to be easily used by participants. Likewise, the play tools used to improve the atmosphere were employed as often as possible to encourage participation. For example, the sessions incorporated many types of background music, including the national physical exercise song, ballet music, traditional Korean ballads, and Korean pop music. The participants were encouraged to engage in light physical activities, such as exercises using a water bottle and volleyball with a balloon. They made paper flowers out of traditional Korean paper to stimulate warm and friendly emotions. They also made picture puzzles to recover their lost cognitive functions. The middle stage of the program $\left(3^{\text {rd }}-6^{\text {th }}\right.$ sessions $)$ was designed to ease depression and promote psychological stability by arousing participants' interests through flexible caring and support. This stage enabled them to focus on recovering residual self-expressive competencies and engaging in play through inter-activity connection and reconstruction. All of the activities contributed to the overall program, which used an integrated approach. Moreover, in each session, the participants made their own play tools; they felt high levels of satisfaction with the play tools they had created themselves.
At the beginning and end of every session, participants were encouraged to form a deeper mutual trust and to participate more expansively in the program by interacting with each other, for example, during musical activities involving familiar play tools, such as the legs subtract game, hula hoops, maracas, tambourines, and triangles, as well as during light physical activities. Members of the research team helped the participants adjust their emotions through play, as a way of learning how to respond effectively to the many problems faced in daily life. This goal was achieved by training the participants to express and share their feelings and opinions. Above all, the participants discovered an ability to search for the meaning and joy of life through positive interactions-for example, by singing songs loudly, holding hands. During the final stage $\left(7^{\text {th }}-8^{\text {th }}\right.$ sessions $)$, they had a discussion and exchanged opinions about the program, sharing joyful experiences and precious memories. Among other activities related to "living" they made needlework corsages and bouquets of roses, chrysanthemum, and babies' breath.

Throughout the program, psychological stability was enhanced through regular encouragement and support. The research team's strategy aimed to stimulate the par- 
ticipants' life energy and establish a pleasant atmosphere, in which every participant could make friends and feel appreciated by others. By making half-moon rice cakes and sharing food brought from home, the participants expressed gratitude to their friends participating in the program and to others who had helped them. To maintain the beneficial effects of the play therapy after the program finished, music CDs, songbooks, computing rods, game marbles, maracas, and tabors were placed in the Town Hall. These were intended to encourage a healthy culture of play to take root in the community, enabling participants to continue making changes to maintain happy lives.

\section{RESEARCH RESULTS}

\section{Homogeneity Test to Compare the Experimental and Control Groups}

By conducting an independent sample $t$-test to verify the pre-test homogeneity of the experimental and control groups, as presented in Table 4, the present study confirmed that the two groups were homogeneous, with no statistically significant differences in self-expression or depression, the variables selected for research before the program.

\section{Effects of Integrated Play Therapy on Self- Expression and Depression}

Table 5 presents the average and standard deviation for each group, confirmed while verifying the effects of integrated play therapy on the self-expression and depression levels of elderly people. Levels of self-expression in the experimental group showed a statistically sig- nificant increase $(p<0.05)$ in the pre-, post-, and follow-up tests, at $2.96 \pm 0.454,3.45 \pm 0.703$, and $4.13 \pm$ 0.164 , respectively. These findings reveal that integrated play therapy expanded self-expression and reduced levels of depression at statistically significant levels (0.85 \pm $0.123,0.67 \pm 0.124$, and $0.21 \pm 0.131$ in the pre-, postand follow-up tests), confirming that integrated play therapy is an effective way of reducing depression among elderly people.

To test whether the equality of regression slope of the dependent variable for the covariates of each group was fulfilled, the covariates (the pre-test scores for selfexpression and depression and the interaction between groups) were introduced into the model; the covariate analysis results are presented in Table 6 . The equality of the regression slope indicates that the post-test and follow-up test scores for self-expression and the post-test scores for depression worked identically in the experimental and control groups; by contrast, the follow-up test scores for depression did not work identically in the experimental and control groups.

An ANCOVA was carried out to verify whether the post- and follow-up test scores for self-expression and depression in the two groups had statistically significant differences; the results are presented in Table 7 . In the case of both self-expression $(\mathrm{F}=4.436 \rightarrow 82.073, \mathrm{p}<$ $.001)$ and depression $(\mathrm{F}=18.458 \rightarrow 216.60, \mathrm{p}<.001)$, a statistically significant difference was observed between the experimental group and the control group. These results indicate that levels of self-expression and depression improved more in the experimental group, which participated in integrated play therapy, than in the control group.

Table 4. Verification of homogeneity between experimental group and control group

\begin{tabular}{ccccc}
\hline \multirow{2}{*}{ Variable } & Experimental group & Control group & \multirow{2}{*}{$t$} & \multirow{2}{*}{$p$} \\
\cline { 2 - 3 } & $M \pm S D$ & $M \pm S D$ & & -1.782 \\
Self-expression & $2.96 \pm 0.454$ & $3.18 \pm 0.433$ & 0.081 \\
Depression & $0.85 \pm 0.123$ & $0.82 \pm 0.126$ & 0.759 & 0.451 \\
\hline
\end{tabular}

Table 5. Mean and standard deviation of self-expression and depression $(M \pm S D)$

\begin{tabular}{|c|c|c|c|}
\hline Variable & Pre - Post - Follow-up & Experimental group & Control group \\
\hline \multirow{5}{*}{$\begin{array}{c}\text { Self- } \\
\text { expression }\end{array}$} & Pre & $2.96^{\mathrm{a}} \pm 0.454$ & $3.18^{\mathrm{a}} \pm 0.433$ \\
\hline & Post & $3.45^{\mathrm{b}} \pm 0.703$ & $3.10^{\mathrm{a}} \pm 0.358$ \\
\hline & Follow-up & $4.13^{\mathrm{c}} \pm 0.164$ & $3.08^{\mathrm{a}} \pm 0.532$ \\
\hline & Pre - post correction average & 3.21 & 3.14 \\
\hline & Post - Follow up correction average & 3.79 & 3.10 \\
\hline \multirow{5}{*}{ Depression } & Pre & $0.85^{\mathrm{a}} \pm 0.123$ & $0.82^{\mathrm{a}} \pm 0.126$ \\
\hline & Post & $0.67^{\mathrm{b}} \pm 0.124$ & $0.83^{\mathrm{a}} \pm 0.134$ \\
\hline & Follow-up & $0.21^{\mathrm{c}} \pm 0.154$ & $0.80^{\mathrm{a}} \pm 0.131$ \\
\hline & Pre - post correction average & 0.76 & 0.82 \\
\hline & Post - Follow up correction average & 0.44 & 0.82 \\
\hline
\end{tabular}

a,b,c: Value of significantly different between the pre-, post, and follow-up test in row $(p<0.05)$ 
Table 6. Identification of rare linear slopes of self-expression and depression

\begin{tabular}{|c|c|c|c|c|c|c|}
\hline \multicolumn{2}{|c|}{ Division } & Variable source & $\begin{array}{l}\text { Sum of } \\
\text { squares }\end{array}$ & $\begin{array}{l}\text { Degree of } \\
\text { freedom }\end{array}$ & $\begin{array}{c}\text { Average of sum of } \\
\text { squares }\end{array}$ & F \\
\hline \multirow{10}{*}{$\begin{array}{c}\text { Self- } \\
\text { expression }\end{array}$} & \multirow{5}{*}{ Post } & Covariance & 0.182 & 1 & 0.182 & 0.001 \\
\hline & & Group & 0.311 & 1 & 0.311 & 0.002 \\
\hline & & Interaction & 15.813 & 1 & 15.813 & 0.123 \\
\hline & & Error & 5911.998 & 46 & 128.522 & \\
\hline & & All & 220777 & 50 & & \\
\hline & \multirow{5}{*}{ Follow-up } & Covariance & 0.022 & 1 & 0.022 & 0.000 \\
\hline & & Group & 181.532 & 1 & 181.532 & 2.905 \\
\hline & & Interaction & 11.348 & 1 & 11.348 & 0.182 \\
\hline & & Error & 2874.918 & 46 & 62.498 & \\
\hline & & All & 269349 & 50 & & \\
\hline \multirow{10}{*}{ Depression } & \multirow{5}{*}{ Post } & Covariance & 2.427 & 1 & 2.427 & 0.158 \\
\hline & & Group & 25.174 & 1 & 25.174 & 1.636 \\
\hline & & Interaction & 6.820 & 1 & 6.820 & 0.443 \\
\hline & & Error & 707.913 & 46 & 15.389 & \\
\hline & & All & 25994 & 50 & & \\
\hline & \multirow{5}{*}{ Follow-up } & Covariance & 2.997 & 1 & 2.997 & 0.189 \\
\hline & & Group & 5.559 & 1 & 5.559 & 0.350 \\
\hline & & Interaction & 135.943 & 1 & 135.943 & $8.561^{* *}$ \\
\hline & & Error & 730.423 & 46 & 15.879 & \\
\hline & & All & 16558 & 50 & & \\
\hline
\end{tabular}

Table 7. Covariance analysis of self-expression and depression between the post and follow-up group

\begin{tabular}{|c|c|c|c|c|c|c|}
\hline \multicolumn{2}{|c|}{ Division } & \multirow{2}{*}{$\begin{array}{c}\text { Variable source } \\
\text { Covariance }\end{array}$} & \multirow{2}{*}{$\begin{array}{r}\begin{array}{c}\text { Sum of } \\
\text { squares }\end{array} \\
0.029\end{array}$} & \multirow{2}{*}{$\begin{array}{c}\begin{array}{c}\text { Degree of } \\
\text { freedom }\end{array} \\
1\end{array}$} & \multirow{2}{*}{$\begin{array}{c}\begin{array}{c}\text { Average of sum of } \\
\text { squares }\end{array} \\
0.029\end{array}$} & \multirow{2}{*}{$\frac{F}{0.000}$} \\
\hline \multirow{8}{*}{$\begin{array}{c}\text { Self- } \\
\text { expression }\end{array}$} & \multirow{5}{*}{ Post } & & & & & \\
\hline & & Group & 559.432 & 1 & 559.432 & $4.436^{*}$ \\
\hline & & Error & 5927.811 & 47 & 126.124 & \\
\hline & & All & 220777 & 50 & & \\
\hline & & Covariance & 0.134 & 1 & 0.134 & 0.002 \\
\hline & \multirow{3}{*}{ Follow-up } & Group & 5040.104 & 1 & 5040.104 & $82.073^{* * *}$ \\
\hline & & Error & 2886.266 & 47 & 61.410 & \\
\hline & & All & 269349 & 50 & & \\
\hline \multirow{8}{*}{ Depression } & \multirow{5}{*}{ Post } & Covariance & 2.307 & 1 & 2.307 & 0.152 \\
\hline & & Group & 280.692 & 1 & 280.692 & $18.458^{* * *}$ \\
\hline & & Error & 714.733 & 47 & 15.207 & \\
\hline & & All & 25994 & 50 & & \\
\hline & & Covariance & 3.635 & 1 & 3.635 & 0.197 \\
\hline & \multirow{3}{*}{ Follow-up } & Group & 3992.640 & 1 & 3992.640 & $216.60^{* * *}$ \\
\hline & & Error & 866.365 & 47 & 18.433 & \\
\hline & & All & 16558 & 50 & & \\
\hline
\end{tabular}

${ }^{*} p<.05, * * p<.01, * * * p<.001$

As presented in Figure 1, the pre-, post-, and follow-up test scores of the experimental and control groups show that the average variants for self-expression and depression in the experimental group showed a more significant difference than those in the control group. These results prove that integrated play therapy can increase self-expression and maintain this expanded level of self-expression; it also reduces levels of depres- sion and maintains them at a reduced level. These results were achieved through an integrated approach, which gave elderly women who lived alone increased self-confidence and a sense of achievement. The participants came to believe that they could do anything; they made play tools that they could use easily and have fun with, connecting their rich life experiences to the constructive environment of play in a harmonious way. 
Self-Expression

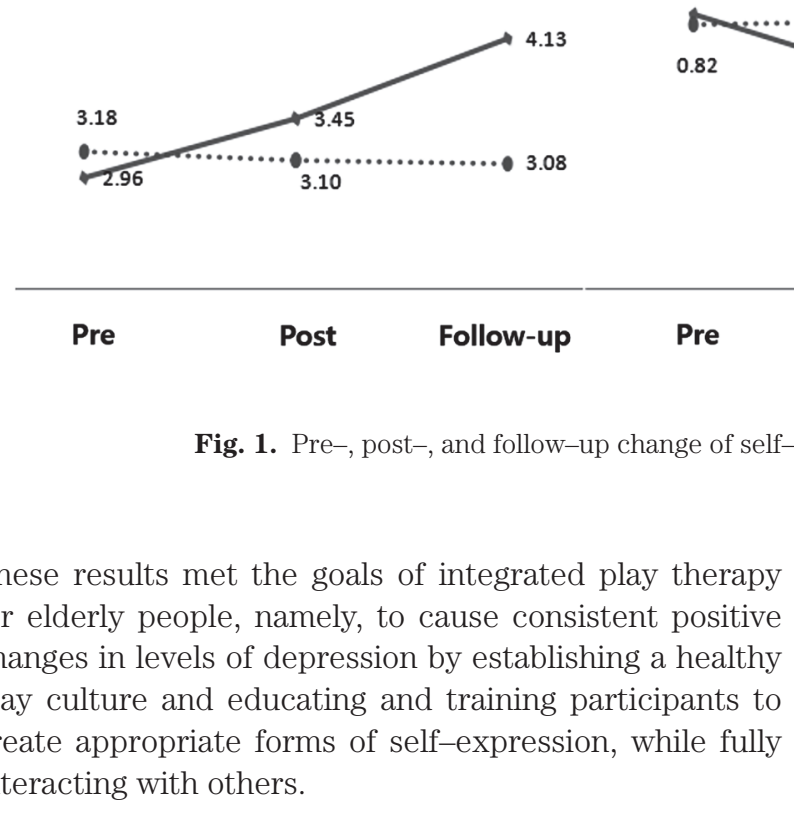

\section{CONCLUSIONS AND SUGGESTIONS}

This study aimed to help elderly women who lived alone in rural areas to pursue psychological and social wellbeing by preventing or reducing depression, a negative emotion, by expanding appropriate forms of selfexpression. Self-expression a primary human function, needed to develop interpersonal relationships. The research team delivered integrated play therapy and checked the participants' pre-, post- and follow-up test results, identifying the variants of each variable and confirming the effects of intervention through a comparison with the pre-, post-, and follow-up test results of a nonequivalent control group.

The key study results are as follows. First, it was observed that integrated play therapy had the effect of expanding self-expression among the elderly participants, who women were living alone in a rural area; the therapy also maintained this expanded self-expression. The results of the present study are supported by Kim (2004), who applied art therapy to a group of low-income elderly women who lived alone; Baek and Oh (2017), who applied art therapy to a group of elderly women who lived alone in a rural area; and Reynolds et al. (2008), who carried out art therapy work with elderly women aged 65-72. The present study shows that play therapy has a greater impact on this population when the intervention is carried out in an integrated way. In addition, this study is significant in demonstrating that a play-therapy approach, in which participants remain interested and participate regularly and consistently in the program, will enable the participants' newfound selfexpression to continue to work positively after the study has finished.

Second, it was observed that integrated play therapy reduced levels of depression in the elderly participants and maintained their depression at a reduced level.
These results are supported by Yoon and Shim (2013), who applied group music therapy to elderly women living alone; Jang (2015), who carried out group art therapy among low-income elderly women living alone; and McCaffrey (2007), who used gardening and art therapy in the "living" area to help elderly women suffering from depression. The present study confirms that play therapy, used in daily life, can reinvigorate the life energy of participants and effectively prevent or reduce depression, a negative emotion frequently experienced by elderly women who have been widowed and suffered other losses in rural areas. Integrated play therapy has also been shown to be effective in enhancing the psychological and social wellbeing of participants through repetitive education and training; it accomplishes this by reinterpreting and reconstructing the familiar play program that all of us have experienced since childhood.

Based on the study results summarized above, we propose the following suggestions. First, elderly women who live alone in rural areas often find it difficult to express conflicting emotions simultaneously, as noted by cognitive developmental approaches that explore emotions and appropriate expressions. For this reason, integrated play therapy can be a very effective clinical intervention for such people, helping them resolve problems in other aspects of their lives and cope with the emotions aroused by conflicts (Harter, 1977). However, most previous studies conducted in South Korea and abroad have used and verified the effects of play therapy on selfexpression while working with groups of infants or children, sometimes on behalf of schools. Vibrant social discussions and policy support are needed to provide diverse educational opportunities for elderly women living alone in rural areas. Such interventions can help them adapt to their environment, improve their capacity for self-expression, make social contributions, move their lives in a positive direction, enhance their quality of life, and fulfill their transcendental needs.

Second, finding an effective therapeutic method that works quickly to relieve emotional conditions such as depression has long been the goal of clinical practitioners (Solomon, 1938). Integrated play therapy for elderly people is a new and very effective approach that directly treats depression. Play therapy interventions will also 
provide information on the ways in which elderly women in rural areas respond to the surrounding environment. Helping them cope with the chronic disease of depression by assigning a leading role to each participant in play therapy and allowing them to create an unlimited number of life situations can enhance their quality of life. We therefore propose an expanded program of integrated play therapy for elderly people, specifically combining play therapy with programs designed to alleviate depression.

Third, most of the play therapy research conducted between 1942 and 2000 has emphasized the need to design an integrated, themed structure for issues and participants, enabling subjects who experience particular problems to access and use information easily (Bratton and Ray, 2000). In fact, individual play therapy studies have ignored the importance of clinical interventions and the integrating effect of related variables, such as self-concept, behavioral control, social skills, emotional control, cognitive functions, and anxiety, all of which play therapy can address, in the case of elderly people. Future studies should explore ways to implement integrated play therapy programs for elderly people, particularly as an intervention to support elderly women living alone in rural areas. Such programs could have a significant impact on social welfare practice and clinics, the national management system, and other mental health issues.

This study has some limitations. The study subjects were recruited from a particular region and the sample size and experimental conditions for research were limited. However, this study is significant because it used integrated play therapy to maximize the effects of education in a group of elderly people, verifying the therapeutic effects and the extent to which they were maintained after the program ended. There is a need for follow-up research to develop intervention programs for people with depression across a wide range of age groups. Further research can also expand the subject groups and target areas, applying a combination of qualitative and quantitative research methods.

\section{AUTHOR CONTRIBUTIONS}

Tae Young KIL, Ph. D; Experimental Design and performed program, manuscript writing.

Han Su RYU, Ph. D; Data analysis, manuscript writing. Nobuhiko YAMAUCHI, Ph. D; Manuscript editing.

\section{AUTHOR DISCLOSURE STATEMENT}

None of the authors have any competing financial interests to declare.

\section{REFERENCES}

Alberti, R. E. and M. L. Emmons 1970. Your perfect right: a guide to assertive behavior. San Luis Obispo of California, CA

Baek, H. H and H. S. Oh 2017 A narrative study on the experience of art therapy among elderly women living alone in rural areas. Korean Journal of Art Therapy 24: 577-600
Bratton, S. and D. Ray 2000 What the research shows about play therapy. Journal of Play Therapy 9: 47-88

Byun, C. J. and S. H. Kim. 1980 Assertiveness training program. Journal of student life guidance 13: 51-85

Case, C. and T. Dalley 2014 The handbook of art therapy. Routledge, New York

Chun, H. T., S. H. Cho and S. J. Cho 2005 A study of geriatric depression propensity based on hearing loss of the old. Audiology 1: 51-58

Collins, N. L. and L. C. Miller 1994 Self-disclosure and liking: a meta-analytic review. Psychological bulletin 116: 457-475

Desrosiers, J., D. Bourbonnais, L. Noreau, A. Rochette, G. Bravo and A. Bourget 2005 Participation after stroke compared to normal aging. Journal of Rehabilitation Medicine 37: 353-357

Drewes, A. A., S. C. Bratton and C. E. Schaefer 2011 Integrative play therapy. John Wiley \& Sons, Canada

Granbom, M., I. Himmelsbach, M. Haak, C. Löfqvist, F. Oswald, and S. Iwarsson 2014 Residential normalcy and environmental experiences of very old people: Changes in residential reasoning over time. Journal of Anthropological Research 31: 34-50

Hackeney, H. and L. S. Ney 1973 Counseling strategies and objective. Englewood \& Cliffs, N T

Harter, S. 1977 A cognitive-developmental approach to children's expression of conflicting feelings and a technique to facilitate such expression in pay therapy. Journal of Consulting and Clinical Psychology 45: 417-432

Hong, S. H., N. Y. Lim and Y. M. Song 2015 A case study of the effect of art therapy on the depression and self-expression of deaf elderly individuals. Korean Journal of Art Therapy 22 1875-1897

Jacobs, P. G., P. M. Brown and L. Paatsch 2012 Social and professional participation of individuals who are deaf: utilizing the psychosocial potential maximization framework. The Volta Review: Washington 112: 37-62

Jang, D. Y. 2015 A case study of group art therapy for reducing depression for low-income older women living alone. Thesis of Master, The Graduate School of Ewha Womans University, Seoul

Jung, I. K., D. I. Kwak, D. K. Shin, M. S. Lee, H. S. Lee and J. Y. Kim 1997 A reliability and validity study of geriatric depression scale. Journal of the korean neuropsychiatric association 36: 103-112

Kapitan, L. 2012 Introduction to Art Therapy Research and Social Action. Jessica Kingsley, London

Kapitan, L. 2017 Introduction to Art Therapy Research. Routledge, New York

Kil, T. Y. 2017 The effect of integrated play therapy with elderly program on self-expression and depression of the elderly with disabilities. Journal of Disability and Welfare 37: 193-215

Kim, H. J. 2008 A case study on the group art therapy to improve the self-expression of old-aged stroke survivors. Korean Journal of Art Therapy 15: 741-760

Kim, J. B. 2000 Curriculum Integration, Kyoyookbook Press, Kyeongki-do

Kim, J. S. 2013 The effects of subject-centered integrative play therapy programs to decrease the level of depression and suicidal ideation of the elderly in nursing home, Thesis of Master, Graduate School of Kyungwoon University, Seoul

Kim, N. M. 2004 Experience of art therapy activities of low income aged women living alone from the viewpoint of narrative inquiry method. Thesis of master, The Graduates School of Professional Therapeutic Technology of Seoul Women's University, Seoul

Kim, Y. K. 2011 The effect of group theraplay on self-esteem and depression of the elderly in day care center. Korean Journal of Counseling 12: 1527-1544

Krause, N. 2007 Self-Expression and Depressive Symptoms in Late Life. Research on Aging 29: 187-206

Landreth, G. L. 2012 Play therapy: The Art of the Relationship. Routledge. New York

Landreth, G. L. 2013 Innovations in Play Therapy. Routledge, New York 
Landreth, G. L., D. C. Ray and S. C. Bratton 2009 Play therapy in elementary schools", Psychology in the School 46: 281-289

Ledyard, P. 1999 Play Therapy with the elderly: A case study. Journal of Play Therapy 8: 57

Lee, J. K. 2012 Factors Affecting the Depression and Anxiety in the Older Adults with Disability. Journal of Social Science $\mathbf{2 3}$ : 189-212

McCaffrey, R. 2007 The effect of healing gardens and art therapy on older adults with mild to moderate depression. Journal of Holistic Nursing Practice 21: 79-84

National Agricultural Cooperative Federation. 2017 Rural Population Trends. Seoul

Parker, R. G. and R. Parrott 1995 Patterns of Self-Disclosure across Social Support Networks: Elderly, Middle-Aged, and Young Adults. Journal of Aging and Human Development 41: 281-297

Potts, M. K. 1997 Social Support and Depression among Older Adults Living Alone: The Importance of Friends within and outside of a Retirement Community. Social Work 42: 348-362

Reynolds, F., K. H. Lim and S. Prior 2008 Narratives of therapeutic art-making in the context of marital breakdown: older women reflect on a significant mid-life experience. Journal of Counselling Psychology Quarterly 21: 203-2104

Rittironga, J., P. Prasartkula and R. R. Rindfussb 2014 From Whom do Older Persons Prefer Support? The Case of Rural Thailand. Journal of Aging Studies 31: 171-181

Ryan, B. and P. Crawford 2002 Creating Loss Support Groups for the Elderly. Social Work with Groups, Mining the Gold, New York

Schaefer, C. E. 2003 Play Therapy with Adults. John Wiley \& Sons, Canada

Schaefer, C. E. and K. J. O'Connor 1994 Handbook of Play Therapy, Advances and Innovations. John Wiley \& Sons, Canada

Shin, H. W. 2014 Play therapy for the elderly. Knowledge Community Press, KyeongKi-do

Shin, H. W. and S. D. Chung 2015 Program development and evaluation of integrative play therapy for older people with suspected early dementia. Korean Association of Psychological
Rehabitation for Children 19: 95-109

Shin, J. H. 2008 An investigation into the design of theme unitcentric integrated learning and integrated performance evaluation. Journal of Research in Curriculum \& Instruction 12 769-787

Solomon, J. C. 1938 Active play therapy. Journal of Orthopsychiatry 8: 479-498

Statistics Korea 2017 Population Census. Seoul.

Stephenson, R. C. 2006 Promoting self-expression through art therapy. Generations 30: 24-26

Suh, M. K. 1990 The buffering effect of social support on the elderly's mental well-being: the case of korean elderly. Journal of the Korean Gerontological Society 10: 68-86

Sung, Y. H. 2009 Play Therapy. Hyungseul Press. Seoul.

Sutherland, D. and E. Murphy 1995 Social support. Among elderly in two community programs. Journal of Gerontol Nurs $\mathbf{2 1}$ 31-38

Taqui, A. M., A. Itrat, W. Qidwai and Z. Qadri 2007 Depression in the elderly: Does family system play a role? A cross-sectional study. BMC Psychiatry 7: 57

Weir, K. N. 2008 Using integrative play therapy with adoptive families to treat reactive attachment disorder. Journal of Family Psychotherapy 23: 1-16

Won, M. R. and K.J. Lee 2016 A study on the experience of depression in elderly women living alone. Journal of Korean Academy of Psychiatric and Mental Health Nursing 25: 195206

Yeh, S. C. and S. K. Lo 2004 Living alone, social support, and feeling lonely among the elderly. Social Behavior and Personality 32: 129-138

Yoon, H. J. and U. B. Shim 2013 The effects of grouping musical therapy on old solitary women' depression, personal relationship, satisfactions of living. Journal Korea Academy of Welfare Counselling Education 7: 1-18

Youn, J. S. 2012 The effects of comprehensive treatment program subjective happiness and depression in the day care center elderly. Korean Journal of 21Century Social Welfare 9: $121-141$ 